\title{
A study on premenstrual syndrome among adolescent girl students in an urban area of West Bengal
}

\author{
Ranjana Mandal $^{1}$, Aditya Prasad Sarkar ${ }^{2 *}$, Supriti Ghorai ${ }^{3}$
}

\author{
${ }^{1}$ Department of Physiology, College of Medicine \& Sagar Dutta Hospital, West Bengal, India \\ ${ }^{2}$ Department of Community Medicine, B S Medical College, Bankura, West Bengal, India \\ ${ }^{3}$ North 24, Parganas District Hospital, Barasat, West Bengal, India
}

Received: 08 May 2015

Accepted: 06 June 2015

\section{*Correspondence:}

Dr. Aditya Prasad Sarkar,

E-mail: dradityaprasadsarkar@gmail.com

Copyright: () the author(s), publisher and licensee Medip Academy. This is an open-access article distributed under the terms of the Creative Commons Attribution Non-Commercial License, which permits unrestricted non-commercial use, distribution, and reproduction in any medium, provided the original work is properly cited.

\begin{abstract}
Background: Previous studies in India reported a prevalence of premenstrual syndrome to be $20 \%$ in a general population and severe symptoms in $8 \%$. The present study was conducted to study the socio-demographic characteristics of adolescent school girls, to estimate the proportion of premenstrual syndrome among them and to find out factors associated with premenstrual syndrome, if any.

Methods: It was a cross-sectional descriptive study conducted at a Kolkata city. Data were collected from the students of Class IX to XII in the classroom using pre-tested pre-designed self-administered questionnaire. Total 278 students were included in the study. Data analysis was done with the help of SPSS version 20.0.

Results: The mean age of the students was 15.61 years $\pm 1.3 .54 \%$ of girls reported to have PMS. Out of the affective symptoms in ACOG criteria depression was by $45.7 \%$, anger by $61.2 \%$, irritability by $88.1 \%$, anxiety by $51.8 \%$, confusion by $46.4 \%$, rejection by 24.8 , breast pain by 22.7 , abdominal distension by $37.5 \%$, headache by $40.6 \%$ and swelling of limbs by $5 \%$ of girls.

Conclusions: Proper medical care and psychological counselling should be sought earlier for increased blood flow during menstruation and dysmenorrhoea to get rid of PMS in adolescent girls.
\end{abstract}

Keywords: Premenstrual syndrome, Adolescent girl students, Urban area

\section{INTRODUCTION}

Menstruation is a normal physiological phenomenon in a woman's reproductive life. Among the gynecological problems, menstrual problems are said to be the major ones especially among adolescent females. ${ }^{1}$ Premenstrual syndrome (PMS) is used to describe physical, cognitive, affective and behavioural symptoms that occur cyclically during the luteal phase of the menstrual cycle and resolve quickly at or within a few days of the onset of menstruation. ${ }^{2}$ Previous studies in India reported a prevalence of premenstrual syndrome to be $20 \%$ in a general population and severe symptoms in $8 \% .^{3}$

American College of Obstetrician and Gynaecologist (ACOG) put forward a criteria which consists of any one of the Affective symptoms (Depression, Angry outbursts, Irritability, Anxiety, Confusion and Social withdrawal) and Somatic symptoms (Breast tenderness, Abdominal bloating, Headache and Swelling of extremities). These symptoms should occur in the three prior menstrual cycles during the 5 days before the onset of menses and the symptom must resolve within 4 days of onset of menses and not recur until after day 12 of the cycle. The symptoms must adversely affect social or work related activities. ${ }^{4}$ These conditions are not life threatening but they can seriously decrease the quality of life of many women and affect their mental health and their productivity. ${ }^{5}$

With this background the present study was conducted to study the socio-demographic characteristics of adolescent school girls, to estimate the proportion of premenstrual 
syndrome among them and to find out factors associated with premenstrual syndrome, if any.

\section{METHODS}

The present study was a descriptive study with crosssectional design. It was conducted in Kolkata City. Study period was from July 2014 to August 2014 as this period was found to have maximum attendance of students in previous years. Out of all wards in Kolkata Municipal Corporation, ward number 35 was selected by simple random sampling. Three Higher Secondary Girls' Schools are situated in this ward. Out of them one school was selected by simple random sampling. The name of the selected school was Surah Kanya Vidyalaya, Kolkata -700035. At first the school authority was approached. The purpose of the study was explained to them. Then the data were collected from the students of class IX to class XII who attended the school on the days of data collection. Place of data collection was the class room. Total 278 students could be included in the study. All of the students who were present in school on those days participated in the study. Informed consent was obtained from the students before data collection. Data collection was done with the help of a pre-designed and pre-tested self -administered questionnaire. Questionnaire was translated in Bengali with the help of experts. Again it was retranslated in English to find out the discrepancies.
Students were briefed about how to fill up the questionnaire. 30 minute time was allotted for filling up the questionnaire. ACOG criteria $^{4}$ were used for assessment of PMS. It contains six affective and four somatic symptoms. Symptoms must also meet the following criteria: i) be relieved within 4 days of the onset of menses, without recurrence until at least cycle day 13 , ii) be present in the absence of any pharmacologic therapy, hormone ingestion, or drug or alcohol use, iii) be causing identifiable dysfunction in social or economic performance and iv) occur reproducibly during two cycles of prospective recording.

Data were entered in M S Excel spread sheet. Data were analyzed with the help of statistical software SPSS version 20.0 using mean, standard deviation, proportion and Chi square test.

\section{RESULTS}

The mean age of the students was 15.61 years \pm 1.3 (Range 13-19 years) (Table 1). All of them were Hindu and residing in Kolkata. Majority belonged to general caste $(84.5 \%)$. $68.3 \%$ of students came from nuclear families. $4.7 \%$ of mothers of the girls were illiterate while $91.7 \%$ girls' mother was educated up to secondary or more. In majority of them, mothers were home maker $(87.4 \%)$ by occupation. BPL card was present in only $9.7 \%$ of students.

Table 1: Distribution of adolescent girls according to socio-demographic factors and premenstrual syndrome $(\mathbf{n}=\mathbf{2 7 8})$.

\begin{tabular}{|c|c|c|c|c|c|}
\hline \multirow{3}{*}{ Factors } & \multicolumn{4}{|c|}{ Premenstrual syndrome } & \multirow{3}{*}{$X^{2}$ value, $p$ value } \\
\hline & \multicolumn{2}{|c|}{ Present } & \multicolumn{2}{|c|}{ Absent } & \\
\hline & No. & $\%$ & No. & $\%$ & \\
\hline \multicolumn{6}{|l|}{ Age(in years) } \\
\hline $13-15$ & 77 & $(58.3)$ & 55 & $(41.7)$ & $1.94,0.16$ \\
\hline $16-19$ & 73 & $(50.0)$ & 73 & $(50.0)$ & \\
\hline \multicolumn{6}{|l|}{ Caste } \\
\hline General & 116 & $(51.6)$ & 109 & $(41.4)$ & $2.73,0.09$ \\
\hline Scheduled caste & 34 & $(64.2)$ & 19 & $(31.8)$ & \\
\hline \multicolumn{6}{|l|}{ Type of family } \\
\hline Nuclear & 104 & $(54.7)$ & 86 & $(44.3)$ & $0.14,0,70$ \\
\hline Joint & 46 & $(52.3)$ & 42 & $(47.7)$ & \\
\hline \multicolumn{6}{|l|}{ Literacy status } \\
\hline Illiterate & 10 & $(43.5)$ & 13 & $(56.5)$ & $1.10,0.29$ \\
\hline Literate & 140 & $(54.9)$ & 115 & $(45.1)$ & \\
\hline \multicolumn{6}{|l|}{ Occupation } \\
\hline Housewife & 129 & $(53.1)$ & 114 & $(46.9)$ & $0.58,0.44$ \\
\hline Others & 21 & $(60.0)$ & 14 & $(40.0)$ & \\
\hline \multicolumn{6}{|l|}{ BPL card } \\
\hline Present & 12 & $(48.0)$ & 15 & $(52.0)$ & $1.08,0.29$ \\
\hline Absent & 138 & $(55.0)$ & 113 & $(45.0)$ & \\
\hline
\end{tabular}


Table 2: Distribution of adolescent girls according to physical factors and premenstrual syndrome $(\mathrm{n}=\mathbf{2 7 8})$.

\begin{tabular}{|c|c|c|c|c|c|}
\hline \multirow{3}{*}{ Physical factors } & \multicolumn{4}{|c|}{ Premenstrual syndrome } & \multirow{3}{*}{$\mathrm{X}^{2}$ value, $\mathrm{p}$ value } \\
\hline & \multicolumn{2}{|c|}{ Present } & \multicolumn{2}{|c|}{ Absent } & \\
\hline & No. & $\%$ & No. & $\%$ & \\
\hline \multicolumn{6}{|l|}{ Age at Menarche } \\
\hline $13-16$ & 90 & $(70.3)$ & 38 & (29.7) & $0.004,0.94$ \\
\hline $17-19$ & 106 & $(70.7)$ & 44 & $(29.3)$ & \\
\hline \multicolumn{6}{|l|}{ Regularity of cycle } \\
\hline Regular & 12 & $(50.0)$ & 12 & $(50.0)$ & $0.166,0.68$ \\
\hline Irregular & 138 & $(54.3)$ & 116 & $(45.7)$ & \\
\hline \multicolumn{6}{|l|}{ Flow } \\
\hline Normal or low & 127 & $(59.3)$ & 87 & $(40.7)$ & $10.86,0.001$ \\
\hline Heavy & 23 & $(35.9)$ & 41 & $(64.1)$ & \\
\hline \multicolumn{6}{|l|}{ Duration of cycle } \\
\hline$\leq 5$ days & 99 & $(55.3)$ & 80 & $(44.7)$ & $0.36,0.54$ \\
\hline$>5$ days & 51 & $(51.5)$ & 48 & $(48.5)$ & \\
\hline \multicolumn{6}{|l|}{ Dysmenorrhoea } \\
\hline Present & 84 & $(47.5)$ & 93 & $(52.5)$ & $8.28,0.004$ \\
\hline Absent & 66 & $(65.3)$ & 35 & $(34.7)$ & \\
\hline
\end{tabular}

Table 3: Distribution of girls according to symptoms in ACOG criteria $(n=278)$.

\begin{tabular}{|lll|}
\hline Symptom & Number & Percentage \\
\hline Depression & 127 & 45.7 \\
\hline Anger & 170 & 61.2 \\
\hline Irritability & 245 & 88.1 \\
\hline Anxiety & 144 & 51.8 \\
\hline Confusion & 129 & 46.4 \\
\hline Rejection & 69 & 24.8 \\
\hline Breast pain & 62 & 22.7 \\
\hline Abdominal distension & 107 & 37.5 \\
\hline Headache & 113 & 40.6 \\
\hline Swelling of limbs & 14 & 5.0 \\
\hline
\end{tabular}

Average age at menarche was 11.98 years \pm 1.08 (Range 9-15 years) (Table 2). Majority of them (91.4\%) had irregular cycles, while flow was more than normal in $23 \%$ girls. Near about two-third of the adolescent girls reported to have cycles longer than 5 days along with dysmenorrhoea.54\% of girls reported to have PMS. Out of the affective symptoms in ACOG criteria $45.7 \%$ reported depression of which $4.7 \%$ suffered frequently in premenstrual period (Table 3). Anger was reported by $61.2 \%$ of girls where $22.7 \%$ was mostly affected. Irritability was reported in as high as $88.1 \%$ girls where $22.7 \%$ experienced it most frequently. Anxiety and confusion were reported by about half of the adolescent girls where about one-tenth had frequent such episodes. Around one fourth of girls experienced breast pain while only $2.2 \%$ experienced it most frequently. $24.8 \%$ of girls also faced social rejection during that period out of them $6.5 \%$ had to face it most frequently. Headache and abdominal distension were reported by around $40 \%$ students. Only $5.4 \%$ of girls had both of these most frequently. Only 5\% of them had limb swelling in premenstrual period, only $1.1 \%$ faced it most frequently.. Premenstrual syndrome was not found to be statistically associated with caste, type of family, education and occupation of mother and possession of BPL card in the family .No statistical significance was observed with age at menarche, duration of cycle and nature of flow. However, it was found to be associated with amount of blood flow during menstruation and presence of dysmenorrhoea $(\mathrm{p}<0.05)$.

\section{DISCUSSION}

Mean age at menarche was found to be more in studies in Erode $^{6}$ and Iran. ${ }^{7}$ Menstrual bleeding was reported to be more in the study at Iran. ${ }^{7}$ Prevalence of PMS was much more in Iran study ${ }^{7}$ and Poland ${ }^{8}$ while it was much less in a study in United Arab Emirates. ${ }^{9}$ In Iranian adolescents the most reported physical symptoms were lower abdominal and back pain and lethargy was the major psychological complaint of respondents ${ }^{7}$ whereas in the present study irritability was commonest psychological and abdominal distension was found to be most common among physical symptoms. Almost one-fourth of the girl students had to face social rejection due to PMS. Like the 
present study dysmenorrhoea was found to be significantly associated with premenstrual syndrome in studies conducted in $\operatorname{Iran}^{7}$ and United Arab Emirates. ${ }^{9}$ However the Erode study did not show any association of PMS with socio-demographic or physical factors while the present study also did not show any association of PMS with socio-demographic factors. ${ }^{6}$

The present study revealed high prevalence of PMS among school going adolescents in an urban area. It was significantly associated with amount of blood flow during menstruation and dysmenorrhoea. Proper medical care and psychological counselling should be sought earlier for this problem. This will help them to get rid of PMS so that they can utilize the formative years of life most.

Funding: No funding sources

Conflict of interest: None declared

Ethical approval: The study was approved by the Institutional Ethics Committee

\section{REFERENCES}

1. Zegeye DT, Megabiaw B, Mulu A: Age at menarche and the menstrual pattern of secondary school adolescents in northwest Ethiopia. Biomed Central Women's Health. 2009;9:29.

2. Braverman PK. Premenstrual syndrome and premenstrual dysphoric disorder. J Pediatr Adolesc Gynecol. 2007;20(1):3-12.
3. Chaturvedi SK, Chandra PS, Issac MK, Sudarshan CY, Beena MB, Sarmukkadam SB, et al. Premenstrual experiences: the four profiles and factorial patterns. J Psychosom Obstet Gynaecol. 1993;14:223-35.

4. ACOG. ACOG practice bulletin: premenstrual syndrome. Int J Gynecol Obstet. 2001;73:183-91.

5. O'Brien PMS. The premenstrual syndrome. A review. J Reprod Med. 1985;30:113-26.

6. Padmavathi P, Sankar SR, Kokilavani NA. Correlation study on premenstrual symptoms among adolescents girls. Asian J Health Sci. 2013;1(1).

7. Delara M, Borzuei H, Montazeri A. Premenstrual Disorders: Prevalence and Associated Factors in a Sample of Iranian Adolescents. Iranian Red Crescent Medical Journal. 2013;15(8):695-700.

8. Premenstrual disorders in Polish adolescent girls: Prevalence and risk factors Drosdzol A, Nowosielski K, SkrzypulecV, Plinta R. Journal of Obstetrics and Gynaecology Research. 2011;37(9):1216-21.

9. Rizk DEE, Mosallam M, Alyan S, Nagelkerke N. Prevalence and impact of premenstrual syndrome in adolescent schoolgirls in the United Arab Emirates. Acta Obstetricia et Gynecologica Scandinavica. 2006;85(5):589-98.

Cite this article as: Mandal R, Sarkar AP, Ghorai S. A study on premenstrual syndrome among adolescent girl students in an urban area of West Bengal. Int $\mathbf{J}$ Reprod Contracept Obstet Gynecol 2015;4:1012-5. 